\title{
Handedness and deformities, radiographic changes, and function of the hand in rheumatoid arthritis
}

\author{
G M MODY, ${ }^{1}$ O L MEYERS, ${ }^{1}$ AND S G REINACH ${ }^{2}$
}

From the ${ }^{1}$ Rheumatic Diseases Unit, Department of Medicine, Groote Schuur and Princess Alice Orthopaedic Hospitals and University of Cape Town; and the ${ }^{2}$ Institute for Biostatistics, South African Medical Research Council

SUMmaRY The correlation of handedness with deformities, radiographic changes, and function of the hand was studied in a large group of patients with rheumatoid arthritis and a dominant right hand. There was no significant difference in the proportion of patients who had swan necko deformity, boutonnière deformity, uncorrectable ulnar deviation, and flexor tenosynovitis in theg dominant and non-dominant hands. There were significantly greater radiological changes in the dominant hand, however, and the middle and index fingers were most severely affected. The severe involvement of these fingers may be related to their greater use in daily activities. There was also more severe functional impairment in the dominant hand.

When patients with hemiplegia or poliomyelitis develop rheumatoid arthritis (RA) the paralysed muscles are either spared or less severely involved. ${ }^{12}$ The most likely explanation for the asymmetrical involvement is the relative lack of use of the paralysed limb. ${ }^{1}$ Physical rest or immobilisation is a beneficial form of treatment and has been shown to have a potent anti-inflammatory effect. ${ }^{34}$ Bone cysts or geodes have been reported more frequently in patients with RA who do heavy manual work because the inflamed synovium may be forced into the porous cancellous bone..$^{5-7}$

The factors which contribute to the development of deformities of the hands are the structural changes of RA together with the forces involved in the use of the hands. ${ }^{8-10}$ Hakstian and Tubiana emphasised the importance of tissue destruction in the production of deformity and stated that external forces of hand use only have a secondary effect. ${ }^{11}$ Hasselkus et al studied the relation between handedness and clinical involvement of the hand in RA and did not find any evidence of significantly greater joint destruction in the dominant hand. ${ }^{12}$ Increased severity of radiographic changes has been reported in the dominant hand, however. ${ }^{13}{ }^{14}$

The aim of this survey was to determine whether there was a relation between handedness and $(a)$ the

Accepted for publication 5 July 1988.

Correspondence to Dr G M Mody, Department of Medicine, University of Natal, PO Box 17039, Congella 4013, South Africa. prevalence of swan neck deformity, flexor tenosynw. vitis, boutonnière deformity, and ulnar deviation (b) the severity of radiographic changes in the hands; $(c)$ the function of the hand based on the assessment of the finger tip to palmar crease distance for all the fingers.

\section{Patients and methods}

A group of 256 patients with classical or definite RA: who were attending the rheumatic diseases unit in Cape Town were studied. All the patients weres interviewed and the handedness of the patient was recorded. The hands were examined to detect the presence of swan neck deformity, boutonnière deformity, uncorrectable ulnar deviation, and flexoo tenosynovitis. Flexor tenosynovitis was considered to be present if the patient had two or more of the following criteria: pain, tenderness or swelling localised to the flexor tendon or tendon sheath, crepitations, snapping, locking, and limitation of digital flexion or extension. ${ }^{15}$ Uncorrectable ulnat deviation was considered to be present if the deformity could not be actively corrected by the patient. The function of the index, middle, ring, anc little fingers was assessed by asking the patient tof? make $a$ fist and the distance from the tip of theo finger to the proximal palmar crease was measured. for each finger. All the patients had standarc posteroanterior radiographs of the hands. These radiographs were graded according to the Larseng 
standard radiographs ${ }^{16}$ by two observers. There was very good agreement in the grading by the two observers $(96 \%$ for the metacarpophalangeal joints and $95 \%$ for the proximal interphalangeal joints).

Two hundred and thirty three patients had a dominant right hand, and their data were analysed. Information about the prevalence of swan neck deformity, boutonnière deformity, ulnar deviation, and flexor tenosynovitis was recorded for the 233 patients. The measurement of the finger tip to palmar crease distance was available in 224 patients. Some of the 233 patients with a dominant right hand had had an operation to the hands or severe deformities where radiographic grading was not possible. Two hundred and ten patients had radiographs that could be analysed for most of the joints

Table 1 Prevalence of swan neck deformity, boutonnière deformity, flexor tenosynovitis, and ulnar deviation in the different fingers $(n=233)$

\begin{tabular}{|c|c|c|c|c|c|c|}
\hline \multirow[t]{2}{*}{ Deformity } & & \multicolumn{5}{|l|}{ Digit } \\
\hline & & Thumb & Index & Middle & Ring & Little \\
\hline \multirow{2}{*}{$\begin{array}{l}\text { Swan neck } \\
\text { deformity }\end{array}$} & $(\mathrm{R})^{*}$ & & 25 & 33 & 31 & 31 \\
\hline & (L) & & 30 & 41 & 32 & 25 \\
\hline \multirow{2}{*}{$\begin{array}{c}\text { Boutonnière } \\
\text { deformity }\end{array}$} & (R) & & 3 & 24 & 25 & 10 \\
\hline & (L) & & 4 & 19 & 20 & 18 \\
\hline \multirow{2}{*}{$\begin{array}{l}\text { Flexor } \\
\text { tenosynovitis }\end{array}$} & (R) & 11 & 74 & 63 & 30 & 21 \\
\hline & (L) & 23 & 54 & 46 & 30 & 25 \\
\hline \multirow[t]{2}{*}{ Ulnar deviation } & (R) & & 20 & 23 & 24 & 26 \\
\hline & (L) & & 24 & 25 & 22 & 21 \\
\hline
\end{tabular}

${ }^{*} \mathrm{R}=$ right; $\mathrm{L}=$ left. (the proximal interphalangeal joint of the index finger could not be graded in the right hand in one patient and in the left hand in another patient). Thus comparison of the radiographic scores of the dominant and non-dominant hand was based on 210 patients unless the index finger was included when the analysis was based on 208 patients.

\section{STATISTICAL METHODS}

McNemar's test and the paired $t$ test were used for statistical analysis of the data. The level of significance for these tests should be adapted for multiple comparisons according to Bonferroni. ${ }^{17}$ As this was a probing survey this adaptation was not taken into consideration and $p$ values of $<0.05$ are reported as significant. The exact probabilities to four decimal places are reported so that corrections for multiple comparisons can be made.

\section{Results}

DEFORMITIES OF THE FINGERS

Table 1 shows the prevalence of flexor tenosynovitis, swan neck deformity, boutonnière deformity, and ulnar deviation in the different fingers of the right and left hand. There was no significant difference in the proportion of patients with swan neck deformity, boutonnière deformity, flexor tenosynovitis, and uncorrectable ulnar deviation in the right hand compared with the left hand.

RADIOGRAPHIC FINDINGS

Table 2 shows the mean Larsen scores for all the

Table 2 Comparison of the Larsen score for the proximal interphalangeal and metacarpophalangeal joints of the right and left hands. Values are mean (SD)

\begin{tabular}{|c|c|c|c|c|}
\hline \multirow[t]{2}{*}{ Joint } & \multicolumn{2}{|l|}{ Larsen score } & \multirow[t]{2}{*}{ Number } & \multirow[t]{2}{*}{ p Value* } \\
\hline & Right hand & Left hand & & \\
\hline IPt thumb & $1 \cdot 443(1 \cdot 102)$ & $1.405(1.027)$ & 210 & 0.4940 \\
\hline PIPt index & $1.699(1.173)$ & $1.512(1.097)$ & 209 & 0.0019 \\
\hline PIP middle & $1.967(1.321)$ & $1.719(1.254)$ & 210 & 0.0030 \\
\hline PIP ring & $1.900(1.422)$ & $1.771(1.270)$ & 210 & $0 \cdot 1112$ \\
\hline PIP little & $1 \cdot 838(1 \cdot 370)$ & $1.686(1.216)$ & 210 & $0 \cdot 0478$ \\
\hline Mean of all PIP + IP thumb & $8 \cdot 838(5 \cdot 238)$ & $8 \cdot 086(4 \cdot 721)$ & 208 & $0 \cdot 0004$ \\
\hline MCPt thumb & $1 \cdot 867(1 \cdot 276)$ & $1 \cdot 695(1 \cdot 121)$ & 210 & $0 \cdot 0336$ \\
\hline MCP index & $2.462(1.593)$ & $2.409(1.575)$ & 210 & 0.5301 \\
\hline MCP middle & $2.252(1.502)$ & $2.176(1.513)$ & 210 & $0 \cdot 3882$ \\
\hline MCP ring & $1.924(1.432)$ & $1.790(1.395)$ & 210 & 0.0848 \\
\hline MCP little & $2 \cdot 114(1 \cdot 517)$ & $1 \cdot 833(1 \cdot 385)$ & 210 & $0 \cdot 0005$ \\
\hline Mean of all MCP & $10 \cdot 619(6 \cdot 125)$ & $9.905(5.819)$ & 210 & $0 \cdot 0024$ \\
\hline Mean of all PIP + MCP & $19 \cdot 470(10 \cdot 403)$ & $17.990(9 \cdot 486)$ & 208 & $<0 \cdot 0001$ \\
\hline
\end{tabular}

*Paired $t$ test.

+IP=interphalangeal joint; $P I P=$ proximal interphalangeal joint: $M C P=$ metacarpophalangeal joint . 
individual joints and groups of joints. The mean Larsen score for all the metacarpophalangeal (MCP) and the proximal interphalangeal (PIP) joints (including the interphalangeal joints of the thumb) was significantly higher for the right hand than for the left hand $(\mathrm{p}<0.0001)$. When the MCP and PIP joints were compared separately the mean values for the right hand were also significantly higher than for the left hand. The combined score for each finger (MCP and PIP) was compared with the corresponding finger in the opposite hand, and the values for all the fingers were significantly greater in the right hand (Table 3 ). The mean radiographic scores for the index and middle fingers in the right and left hands were significantly higher than all the other fingers except the right index and little finger where the difference was not statistically significant. There was no significant difference between the index and middle fingers.

\section{ASSESSMENT OF HAND FUNCTION}

Table 4 shows the mean distance from the tip of the finger to the proximal palmar crease for each finger. The overall mean distance for the right hand was greater than for the left hand $(p=0 \cdot 0174)$. The mean values were highest for the index fingers followed by

Table 3 Comparison of the Larsen score for each finger $(M C P+P I P)^{*}$ with the corresponding finger in the opposite hand. Values are mean (SD)

\begin{tabular}{lllll}
\hline Digit & \multicolumn{2}{l}{ Larsen score } & Number & $p$ Valuet \\
\cline { 2 - 4 } & Right hand & Left hand & & \\
\hline Thumb & $3.309(1.991)$ & $3.100(1.729)$ & 210 & 0.0311 \\
Index & $4.167(2.361)$ & $3.933(2.203)$ & 209 & 0.0049 \\
Middle & $4.219(2.339)$ & $3.895(2.277)$ & 210 & 0.0030 \\
Ring & $3.824(2.409)$ & $3.562(2.294)$ & 210 & 0.0164 \\
Little & $3.952(2.480)$ & $3.519(2.141)$ & 210 & 0.0002 \\
\hline
\end{tabular}

${ }^{*} \mathrm{MCP}=$ metacarpophalangeal joint $; \mathrm{PIP}=$ proximal interphalangeal joint.

†Paired $t$ test.

Table 4 Pairwise comparison of the mean values of the finger tip to palmar crease distance for the right and left hands $(n=224)$. Values are mean $(S D)$

\begin{tabular}{llll}
\hline Finger & Right hand & Left hand & $p$ Value \\
\hline Index & $26.013(16.782)$ & $24.017(18.385)$ & 0.0329 \\
Middle & $22.629(20.830)$ & $21.106(21.442)$ & 0.1220 \\
Ring & $19.865(21.594)$ & $17.914(21.122)$ & 0.0377 \\
Little & $12.960(18.708)$ & $11.978(17.229)$ & 0.2442 \\
Mean value & & & \\
$\quad$ per finger & $20.366(17.996)$ & $18.754(17.763)$ & 0.0174 \\
\hline
\end{tabular}

*Paired $t$ test. the middle, ring, and little fingers. The mean $\underline{\square}$. distance for each finger was compared with the distance for the other fingers of the same hand; the $\vec{F}$ values for all the fingers in the left hand were significantly different from each other, whereas in the right hand all the fingers were significantly $\bar{c}$ different from each other except the middle and ring fingers.

\section{Discussion}

The presence of significantly greater damage in the $\overrightarrow{\widetilde{\omega}}$ dominant hand on radiological assessment has been reported by Mattingly et al in a study of 30 patients ${ }^{13} \bar{Q}$ and by Owsianik et al, who studied 20 patients with $\stackrel{\vec{~}}{\oplus}$ RA. ${ }^{14}$ In the present study of 208 patients these findings were confirmed, and there was significantly $\vec{D}$ greater involvement of the dominant hand $(\mathrm{p}<0.0001)$.

Dickson et al measured the flexion and pinch force of the fingers and found that the index and $\stackrel{D}{O}$ middle fingers were significantly stronger than the ring and little fingers. ${ }^{18}$ The earliest erosions in the MCP joints were found to occur in the index and $\overrightarrow{0}$ middle fingers. ${ }^{19}$ Mattingly et al also found that tie MCP joints of the index and middle fingers wete more severely damaged than the MCP joints $\overline{\mathrm{f}}$ other fingers, ${ }^{13}$ and those findings were confirmed in this survey. The combined MCP and PIP joint score for each finger was highest for the index and $\stackrel{0}{8}$ middle fingers. It is likely that the severe changes in $\stackrel{\varnothing}{2}$ the index and middle fingers occur because of the $\overrightarrow{\overrightarrow{0}}$ greater use of these fingers. The combined score for $\exists$ the thumb (MCP and interphalangeal joints) was significantly less than the combined score (MCP and PIP joints) for each of the other fingers in the right $\stackrel{?}{2}$ and left hands. Mattingly $e t$ al also found that the joint damage was least severe in the thumb. ${ }^{13}$

The prevalence of ulnar deviation and handedness has been studied previously and conflicting results have been noted. ${ }^{80-22}$ There were no significant differences in the prevalence of ulnar deviation, $\frac{}{7}$ swan neck deformity, boutonnière deformity, and $\frac{D}{O}$ flexor tenosynovitis in the dominant and nondominant hand in this study.

In conclusion, there was significantly greater $N$ radiographic involvement of the dominant hand, $N$ and the index and middle fingers were most severely $\omega$ involved. The function of the hand was also more severely impaired in the dominant hand. There was $\stackrel{\circ}{\subset}$ no significant difference between the prevalence of $\stackrel{\Phi}{\Phi}$ flexor tenosynovitis, swan neck deformity, boutonnière deformity, and ulnar deviation in the domi- $\frac{0}{\circ}$ nant and non-dominant hand.

This project was supported by a grant from the South African 
Medical Research Council, the Rheumatic Disease Research Fund of the University of Cape Town, and the Arthritis Research Fund of the University of Natal.

\section{References}

1 Thompson M, Bywaters E G L. Unilateral rheumatoid arthritis following hemiplegia. Ann Rheum Dis 1956; 5: 21-5.

2 Glick E N. Asymmetrical rheumatoid arthritis after poliomyelitis. Br Med J 1967; iii: 26-8.

3 Lee P, Kennedy A C, Anderson T, Buchanan W W. Benefits of hospitalization in rheumatoid arthritis. $Q J$ Med 1974; 4: 205-14.

4 Partridge R E H, Duthie J J R. Controlled trial of the effect of complete immobilisation of the joints in rheumatoid arthritis. Ann Rheum Dis 1963; 22: 91-9.

5 Castillo B A, El Sallab R A, Scott J T. Physical activity, cystic erosions and osteoporosis in rheumatoid arthritis. Ann Rheum Dis 1965; 24: 522-7.

6 Gaunt W D, Rinker C T. Gout-like x-rays in active men with rheumatoid arthritis. Mo Med 1970; 67: 225-9.

7 Jayson M I V, Rubenstein D, Dixon A St J. Intra-articular pressure and rheumatoid geodes (bone 'cysts'). Ann Rheum Dis 1970; 29: 496-506.

8 Kemble J V H. Functional disability in the rheumatoid hand. Hand 1977; 9: 234-41.

9 Smith E M, Juvinall R C, Bender L F, Pearson J R. Flexor forces and rheumatoid metacarpophalangeal deformity. JAMA 1966; 198: 150-4.

10 Ellison M R, Flatt A E, Kelly K J. Ulnar drift of the fingers in rheumatoid disease. J Bone Joint Surg [Am] 1971; 53: 1061-82.

11 Hakstian R W, Tubiana R. Ulnar deviation of the fingers. The role of joint structure and function. J Bone Joint Surg [Am] 1967; 49: 299-316.
12 Hasselkus B R, Kshepakaran K K, Safrit J J. Handedness and hand joint changes in rheumatoid arthritis (dominance, goniometry, deformity, joint protection). Am J Occup Ther 1981; 35: 705-10.

13 Mattingly P C, Mattheson J A, Dickson R A. The distribution of radiological joint damage in the rheumatoid hand. Rheumatology and Rehabilitation 1979; 18: 142-7.

14 Owsianik W D J, Kundi A, Whitehead J N, Kraag G R, Goldsmith C. Radiological articular involvement in the dominant hand in rheumatoid arthritis. Ann Rheum Dis 1980; 39: 508-10.

15 Gray R G, Gottlieb N L. Hand flexor tenosynovitis in rheumatoid arthritis. Prevalence, distribution and associated rheumatic features. Arthritis Rheum 1977; 20: 1003-8.

16 Larsen A, Dale K, Eek M. Radiographic evaluation of rheumatoid arthritis and related conditions by standard reference films. Acta Radiol [Diagn] (Stockh) 1977; 18: 481-91.

17 Neter J, Wasserman W. Applied statistical models. Homewood, Illinois: Richard D Irwin, 1974: 730.

18 Dickson R A, Petrie A, Nicolle F V, Calnan J S. A device for measuring the force of the digits of the hand. Biomedical Engineering 1972; 7: 270-3.

19 Martel W, Hayes J T, Duff I F. The pattern of bone erosion in the hand and wrist in rheumatoid arthritis. Radiology 1965; 84: 204-14.

20 Fearnley G R. Ulnar deviation of the fingers. Ann Rheum Dis 1951; 10: 126-36.

21 Treuhaft P S, Lewis M R, McCarty D J. A rapid method for evaluating the structure and function of the rheumatoid hand. Arthritis Rheum 1971; 14: 75-86.

22 Lush B. Ulnar deviation of the fingers. Ann Rheum Dis 1952; 11: $219-21$. 